\title{
Need For Cognition As A Moderator Of Affective And Cognitive Elements In Online Attitude Toward The Brand Formation
}

\author{
Chip E. Miller, Drake University, USA \\ James Reardon, Monfort College of Business, USA \\ Laura Salciuviene, Lancaster University Management School, UK \\ Vilte Auruskeviciene, ISM University of Management, and Economics, Lithuania \\ Kelvin Lee, Singapore Logistics Association, Singapore \\ Kenneth E. Miller, University of Technology, Sydney, Australia
}

\begin{abstract}
Previous research on the web using traditional attitude formation models - dual mediation hypothesis (DMH) and affect transfer hypothesis $(A F H)$ - suggests that DMH holds only for those with high need for cognition. This study examines need for cognition (NFC) as a moderator of the individual contributions of affective and cognitive elements on attitude toward the brand in an online setting. Findings show that as need for cognition increases, the effect of the creative elements in the ad on attitude toward the brand formation is lessened. The opposite effect occurs for cognitive ad elements. Our results further suggest a significant interaction effect of NFC with attitude toward the advertisement.
\end{abstract}

Keywords: Need for Cognition, Attitude toward the Advertisement, Attitude toward the Brand, Attitude Formation

\section{INTRODUCTION}

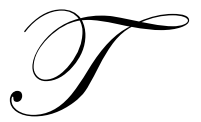

he global impact of the internet on consumer information search has been far reaching and profound. The immense amount of information now at consumers' fingertips, and their ability to manipulate the speed of presentation as well as the content, brings into question whether the traditional models of consumer behavior can be applied without modification to this new medium. Websites, the most common method used by consumers to locate information, permit the searcher to interact with the organization in a manner not seen previously (Coyle and Thorson, 2001; Ha and James, 1998). The volume of information contained in a website is much greater than that traditionally presented to a prospective customer because multiple stakeholders will visit the same site and can direct themselves to different areas at their whim (Hwang, MacMillan and Lee, 2003).

It is this consumer control of the volume and speed of information that makes the web a challenging opportunity for further research. Because the consumer controls message delivery, they must expend more effort than with traditional media to obtain and process information from ads (Ariely, 2000). Nonetheless, there is an expectation that previous models of attitude formation should be as viable in a web environment as in traditional media (Brunner II and Kumar, 2000; Berthon, Pitt and Watson, 1996). Sicilia, Ruiz and Reynolds (2005) made a preliminary study of how the dual mediation hypothesis (DMH) and affect transfer hypothesis (ATH) operated on the web and which hypothesis was more likely to be employed by consumers. The next logical step is to delve deeper into the respective elements forming ads - affective and cognitive - that are at the heart of these models and determine how the consumer's need for cognition (NFC) affects the individual and interactive contributions of affect and cognition toward formation of attitude toward the brand $(\mathrm{Ab})$. 


\section{ATTITUDE FORMATION}

The study of attitude formation has a long and rich history in the consumer behavior literature. Attitudes are what consumers develop after evaluation of a product or service and may be positive or negative (Mitchell and Olson, 1981). One of the more comprehensive models of attitude formation that has spawned a substantial stream of research is the Elaboration Likelihood Model (Petty and Cacioppo, 1981). Their Elaboration Likelihood Model, combined with work by Mitchell (1986), pointed to two outcomes. Peripheral routes to persuasion tended to be influenced by affective elements and led to rather transient attitude formation. In other words, attractive pictures would catch the eye of the viewer and the positive affect they generated would be transferred through attitude toward the ad to the brand itself, with little deep evaluation occurring. Central route processing, which required far more cognitive effort, was expected to occur through verbal elements in the ads and produced more lasting attitude toward the brand.

Related work by Mitchell and Olson (1981) coincides with the ELM model. Pictures were found to have an influence on attitude toward the ad by a different route than cognitive information. Affective elements such as pictures fit perfectly with the peripheral routes of the ELM. Cognitive elements - generally verbal messagescorrespond to the central route.

Level of involvement was found to be a moderator of these results (Petty, Cacioppo and Schumann, 1983). Low involvement, either with the product or the ad itself, tended to result in shallow processing and hence a peripheral route to persuasion. High involvement, shown through greater interest and more willingness to exert greater cognitive effort in evaluation and processing, led to the central route.

Cho (1999) carried this stream of research into Internet advertising. He notes that consumers have far more control of the volume and content of ad material they are exposed to than in traditional media. Internet ads require more conscious cognitive effort. His findings indicate that a modified ELM explains well consumer behavior on the Internet. High involvement consumers are more likely to seek further information through links than low involvement consumers. Low involvement consumers saw increased likelihood to click links when the ad elements of size or animation were affectively pleasing.

Cho's (1999) results are further supported by the work of Das et al. (2003) and Martin, Sherrard and Wentzel (2005). Das et al. (2003) demonstrated that consumers with a high NFC (that is, high involvement customers) will be drawn to the web because of its ability to provide voluminous information on a product. Martin, Sherrard and Wentzel (2005) expanded on this notion by demonstrating that consumers with high NFC preferr websites with more verbal (cognitive) content, while high sensation seeking viewers like more complex visuals. These results parallel traditional findings with regard to peripheral and central processing routes and the types of individuals that rely on each. Central processors tend to have a high NFC and prefer ads with high cognitive content. Indeed, peripheral processors prefer ads with attractive visuals.

A study by Li and Bukovac (1999) found that larger banner ad size and animation resulted in better clickthrough rates. Interestingly, and contrary to other studies, user mode (information seeking vs. surfing) did not affect attitude toward the ad. It would seem more likely that high NFC consumers (i.e. information seeking) would display different attitudes toward the ad than would surfers.

Sicilia, Ruiz and Reynolds (2005) compared two attitude formation models, affect transfer (i.e. peripheral route) [Droge, 1989] and dual mediation (i.e. central route) [Mackenzie, Lutz and Belch, 1986]. Their conclusion was that, overall, an affect transfer model better describes attitude toward the brand formation based on internet sources. Only high NFC subjects' behavior was described by the dual mediation hypothesis.

Following the suggestion of Sicilia, Ruiz and Reynolds (2005), we probe further into the effect of the specific ad elements on the formation of attitude toward the brand as moderated by NFC. We also include high involvement and low involvement goods to ascertain how this affects the outcome. 
Subjects with a high NFC are believed to prefer a central processing route (Silicia, Ruiz and Reynolds, 2005). Ads aimed at high NFC viewers will emphasize the cognitive (verbal, information-rich) elements in the ad. The more cognitive information the ad provides, the better it will be evaluated. This, in turn, will produce a more favorable attitude toward the brand. Thus, we posit that:

H1: The higher the need for cognition, the less pronounced the effect of the creative aspects of attitude toward the ad will be on attitude toward the brand.

H2: The higher the need for cognition, the more pronounced the effect of the cognitive aspects of attitude toward the ad will be on attitude toward the brand.

\section{METHODOLOGY}

Two different banner ads were created for use in this study. The level of information was manipulated in the two ads to vary the appeal for high and low NFC respondents. One banner ad featured soft drinks, while the other was for a personal computer. To appeal to the desires of high NFC respondents, the computer ad was information rich. The soft drink ad, in contrast, had a preponderance of affective elements.

Two online pretests of the ads were conducted in the computer laboratory. All respondents $(n=35)$ were first exposed to both experimental banner ads and then instructed to answer five questions for each ad. A sevenpoint scale (strongly agree $=1$, strongly disagree $=7$ ) was used to measure creative aspects of the advertising. Ttests were conducted for verifying the content orientation. The final pretest results suggested that the computer (high involvement product) banner ad was more informative ( $\bar{x}=2.90, \mathrm{t}$-value $=-4.853, \mathrm{p}=0.010$ ) than entertaining $(\bar{x}=3.60, \mathrm{t}$-value $=-1.293, \mathrm{p}=0.206)$. The soft drink (low involvement product) banner ad was perceived as more entertaining $(\bar{x}=2.47, \mathrm{t}$-value $=-8.275, \mathrm{p}=0.000)$ than informative $(\bar{x}=3.69$, t-value $=-1.204, \mathrm{p}=0.238)$.

\section{Sample Selection and Data Collection}

The sample was recruited by using advertising flyers and invitation emails to Internet users to participate in an online survey. Those interested respondents then received a follow-up email with the Web URL address and an entry into a drawing for a cash incentive. A final sample of 490 respondents was accumulated.

This research utilized attitude scales developed by Gardner (1985), Mitchell (1986), Maheswaran and Sternthal (1990), and Cho (1999) that were modified to apply in the context of Internet advertising to measure online attitudes because they were originally designed for traditional media. Cho's (1999) scales were directly applied in this research to measure attitudes toward the target advertising. Scales to measure purchase intention from Baker and Churchill (1977) and Bone and Ellen (1992) were compared to Cho's (1999) scale and modified. A 7-point Likert scale measures all scales ("1" indicated strongly disagree with the web content (design) about products/brands, and a "7" indicated strongly agree).

Data were collected through three stages. First, respondents were asked about their web use and personality traits. Next, they viewed a dummy online newspaper that appeared as a 'pop-up' window. After they finished browsing the site, the participants were asked to close the window and return to the web questionnaire. Finally, an active online newspaper appeared with one of the experimental banner ads. Following exposure to the ad, they answered questions about their attitudes toward the ad, its elements, attitude toward the brand and toward banner ads. This was followed by questions about the participants' age, gender and educational level.

\section{Measures}

We calculated reliability using Cronbach's alpha. Table 1 depicts the results from these tests. All values were well in excess of 0.80 . We tested the validity and unidimensionality (Gerbing and Anderson, 1988) of the scale with confirmatory factor analysis using LISREL 8.8 (Joreskog and Sorbom, 1993). We tested convergent validity by examining the $\mathrm{t}$-values of the lambda-X matrix (Bagozzi, 1981), and we tested discriminant validity by 
setting the individual paths of the phi matrix to one and testing the resultant model against the original (Gerbing and Anderson 1988), using the D-square statistic (Joreskog and Sorbom, 1993). With the exception of the Attitude toward the Advertisement measures, all results were acceptable. The two Attitude toward the Advertisement measures exhibited lack of unidimensionality. This was to be expected as the items for both measures were taken from more general Attitude toward the Advertisement measures (Mitchell, 1986). However, given the purpose of this research and the face validity of the items, we feel comfortable treating them as separate subdimensions.

Table 1

Construct Measures and Cronbach's Alpha

\begin{tabular}{l}
\hline Construct Items \\
\hline Need For Cognition (NFC) - reduced \\
I like to have the responsibility of handling a situation that requires a lot of thinking. \\
The idea of relying on thought to make my way to the top appeals to me. \\
I really enjoy a task that involves coming up new solutions to problems. \\
I prefer my life to be filled with puzzles that I must solve. \\
I would a task that is intellectual, difficult and important to one that is somewhat important but does not \\
require much thought. \\
Attitude toward the Content of the Advertisement \\
This banner ad is meaningful. \\
This banner ad is relevant to my needs. \\
This banner ad is informative. \\
Attitude toward the Creative of the Advertisement \\
This banner ad has good visual effect. \\
This banner ad is eye-catching. \\
This banner ad draws my attention. \\
Attitude toward the Brand \\
I like the brand I saw on the banner ad. \\
The brand I saw on the banner ad is satisfactory. \\
The brand I saw on the banner ad is desirable. \\
\hline
\end{tabular}

Ranging from 18.19 to 30.89 , all $\mathrm{t}$-values of the lambda-X matrix were well above the 2.00 level that Kumar, Stern and Achrol (1992) specified, indicating high convergent validity of the scales. Tests for discriminant validity indicated that the confirmatory factor model for the scales fit significantly better than the constrained models for each construct, as inferred by high D-square statistics.

\section{Analytical Method}

Figure 1 depicts a SEM model that was run using LISREL 8.80. NFC was treated as a direct effect on Attitude toward the Brand. In addition, the interaction between NFC was used as moderating variable for both measures of Attitude toward the Advertisement (Creative and Content) using a modified two stage approach in LISREL as per Chin, Marcolin and Newstead (2003).

\section{RESULTS}

The fit measures are adequate with the RMSEA (0.078) and GFI (0.91) being slightly better their normally recommended limits ( 0.078 and 0.90 respectively) and the rest of the measures being well into the acceptable range (e.g., NFI, CFI and RFI all above 0.95). Examination of the modification indices indicates that the division of the Attitude toward the Advertisement construct into two separate constructs significantly detracts from the fit measures, as would be expected. However, as indicated earlier, this separation is necessary to test the hypotheses. In addition, the differential effects between the subdimensions indicate further support for this separation (i.e., if they were truly the same, the paths to each would be equal). Table 2 depicts the primary results of the hypotheses. 


\section{Figure 1}

Model

Attitude toward the Ad

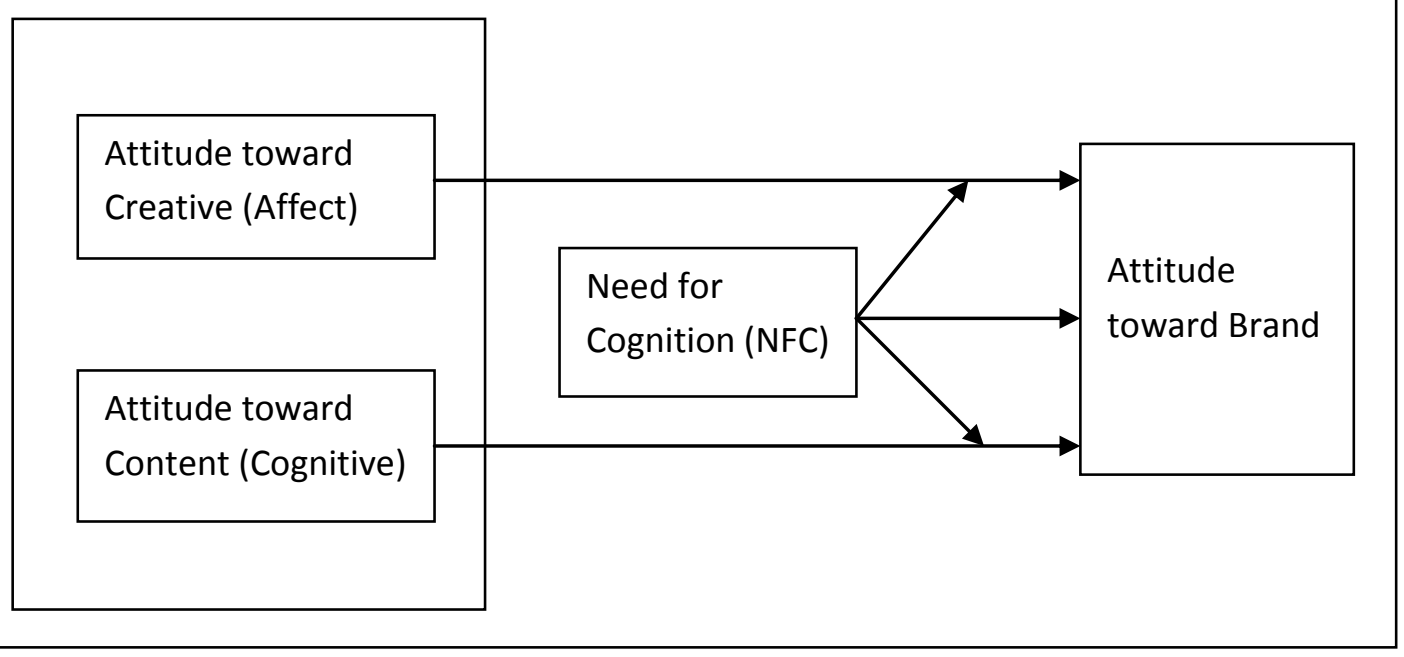

Table 2

Model Results

\begin{tabular}{lccc}
\hline \multicolumn{1}{c}{ Results } & Est. & t/p - value & Hypotheses \\
\hline Main Effects & 0.46 & $7.45 / \mathrm{p}<.001^{*}$ & \\
$\mathrm{Aad}_{\text {Affect }} \rightarrow \mathrm{A}_{\text {brand }}$ & 0.43 & $6.92 / \mathrm{p}<.001^{*}$ & \\
$\mathrm{Aad}_{\text {Cognitive }} \rightarrow \mathrm{A}_{\text {brand }}$ & -0.03 & $1.01 / \mathrm{p}=0.32$ & \\
$\mathrm{NFC} \rightarrow \mathrm{A}_{\text {brand }}$ & & & \\
& & & \\
Interaction Terms & -0.09 & $1.72 / \mathrm{p}=0.044^{*}$ & H1: Supported \\
$\left\{\right.$ Aad $\left._{\text {Affect }} \mathrm{X} \mathrm{NFC}\right\} \rightarrow \mathrm{A}_{\text {brand }}$ & 0.09 & $1.74 / \mathrm{p}=0.043^{*}$ & H2: Supported \\
$\left\{\right.$ Aad $\left._{\text {Cognitive }} \mathrm{X} \mathrm{NFC}\right\} \rightarrow \mathrm{A}_{\text {brand }}$ & & & \\
\hline
\end{tabular}

While not surprising given the previous literature, nor hypothesized here, the attitude toward the advertisement has a strong impact on Attitude toward the Brand. More interesting are the differential and significant interactive effects of NFC and Attitude toward the Ad elements on Attitude toward the Brand. As suggested by the hypotheses, higher NFC moderates the impact of Attitude toward the Ad on Attitude toward the Brand. Higher NFC incrementally increases the effect of Attitude toward the cognitive elements, and decreases the effect of attitude toward the affective elements. Additionally, the findings suggest that NFC has only an indirect effect on formation of attitude toward the brand for online purchases.

\section{CONCLUSIONS AND FUTURE RESEARCH}

As one's NFC rises, the impact of attitude toward the creative elements on attitude toward the brand formation diminishes. Conversely, the consumers' attitude toward the brand is more influenced by the cognitive elements of the ad. The ability of the Internet site to tailor to this outcome is significant. Users who have little or no desire for substantial cognitive content could be directed to more ethereal, entertaining links that reinforce their affective desires and have a positive impact on $\mathrm{Ab}$. Those visitors who wish to collect more information before making a purchase would be able to visit links that feed that need. Suggestions on which links lead to which type of content could easily be provided by the company, enhancing the attitude toward the brand formation and increasing the likelihood of purchase. 
Further research as to the number of links visited and the length of time spent with each one is called for. Other studies suggest that click-through rates have an effect on attitude formation and purchase intent for functional and expressive products (Dahlen and Bergendahl, 2001). However, these products are not the same as high and low involvement. Thus, blending both types of products so that all combinations could be studied would give a more robust result. One aspect not found in other work is the question about whether attitudes formed through peripheral processing could be made as enduring as central route ones if the viewer could control the number and intensity of ad exposures. The ability of Internet users to determine how many links they visit after their primary connection may prove a determining factor in strengthening attitude toward the brand for peripheral processors.

\section{AUTHOR INFORMATION}

Chip Miller is a Professor of Marketing at Drake University. His publications have appeared in Journal of Marketing, Journal of International Marketing and Journal of Marketing Theory and Practice, among others. His research interests include international consumer behavior and marketing management.

James Reardon is a Wells Fargo Professor of Marketing at the Monfort College of Business and the HIT Company Professor at the University of Ljubljana, Slovenia. His publications have appeared in Journal of Marketing, Journal of Retailing, Journal of International Marketing and Journal of Marketing Education, among others. Recently, he was named the UNC Distinguished Scholar. His non-academic background includes managing several businesses in various functions.

Dr Laura Salciuviene is a Lecturer in Marketing at Lancaster University Management School. Her research is multidisciplinary and focuses on marketing strategies in emerging markets and international consumer behavior. She has had articles published in Journal of Marketing Management, International Business Review and Advances in International Marketing.

Dr Vilte Auruskeviciene is a Professor of Marketing and Vice-Dean for Academic Affairs at the ISM University of Management and Economics (Undergraduate School), Lithuania. Her research and teaching interests focus on marketing strategy and relationship marketing. She has presented and has published her research results in conferences and journals.

Dr Kelvin Lee is a Training Centre Director at Singapore Logistics Association. He has an extensive experience working in both healthcare and educational sector where he has worked as Senior Manager in which he oversaw research projects and marketing planning and strategies and subsequently in two private higher education institutions in Singapore as a Director managing the school operations. His research interests are Internet advertising, customer satisfaction and brand management. He has published his research results in journals and conferences.

Professor Ken Miller received his PhD from Ohio State University. He has had articles published in the Journal of Marketing Research, Journal of Consumer Research, Journal of Business Research and Journal of Retailing, among others. He has also co-authored an Australian Marketing and Marketing Research textbooks. He has served on the national committee of the Australian Market and Social Research Society and is past Chairperson of Interviewer Quality Control of Australia (IQCA).

\section{REFERENCES}

1. Ariely, Dan, Controlling the Information Flow: Effects on Consumers' Decision Making and Preference, Journal of Consumer Research, Vol. 27, No. 2, pp. 233-248, 2000.

2. Baggozi, Richard, Evaluating Structural Equation Models with Unobservable Variables and Measurement Error: A Comment, Journal of Marketing Research, Vol. 18, August, pp. 375-381, 1981.

3. Baker, Michael and Gilbert Churchill, The Impact of Physically Attractive Models on Advertising Evaluation, Journal of Marketing Research, Vol. 14, No. 4, November, pp. 538-555, 1977. 
4. Berthon, Pierre, Leyland Pitt and Ricahrd T. Watson, The World Wide Web as an Advertising Medium: Toward an Understanding of Conversion Efficiency, Journal of Advertising Research, Vol. 36, No. 1, pp. 43-54, 1996.

5. Bone, Paula and Pam Ellen, The Generation and Consequences of Communication-Evoked Imagery, Journal of Consumer Research, Vol. 19, No. 1, June, 93-104, 1992.

6. Bruner II, Gordon and Anand Kumar, Web Commercials and Advertising Hierarchy-of-Effects, Journal of Advertising Research, Vol. 40, No. 1/2, pp. 35-42, 2000.

7. Chin, Wynne, Barbara Marolin and Peter Newsted, A Partial Least Squares Latent Variable Modeling Approach for Measuring Interaction Effects: Results from a Monte Carlo Simulation Study and an Elctronic-Mail Emotion/Adoption Study, Information Systems Research, Vol. 14, No. 2, pp. 189-217, 2003.

8. Cho Hang-Choan, How Advertising Works on the WWW: Modified Elaboration Model, Journal of Current Issues and Research in Advertising, Vol. 21, No. 1, pp. 33-50, 1999.

9. Coyle, James and Esther Thorson, The Effects of Progress Levels of Interactivity and Vividness in Web Marketing Sites, Journal of Advertising, Vol. 30, No. 3, pp. 13-28, 2001.

10. Dahlen, Michael and Jonas Bergendahl, Informing and Transforming on the Web: An Empirical Study of Response to Banner Ads for Functional and Expressive Products, International Journal of Advertising, Vol. 20, No. 2, pp. 189-205, 2001.

11. Das, Samar, Raj Echambadi, Michael McCardle and Michael Luckett, The Effect of Interpersonal Trust, Need for Cognition, and Social Loneliness on Shopping, Information Seeking and Surfing on the Web, Marketing Letters, Vol. 14, No. 3, pp. 185-202, 2003.

12. Droge, Cornelia, Shaping the Route to Attitude Change: Central Versus Peripheral Processing through Comparative Versus Non-Comparative Advertising, Journal of Marketing Research, Vol. 26, May, pp. 193-204, 1989.

13. Gardner Meryl P., Does Attitude toward the Ad Affect Brand Attitude under a Brand Evaluation Set? Journal of Marketing Research, Vol. 22, May, pp. 192-198, 1985.

14. Gerbing, David and James Anderson, An Updated Paradigm For Scale Development Incorporating Unidimensionality and Its Assessment, Journal of Marketing Research, Vol. 25, May, pp. 186-192, 1988.

15. Ha, Louisa and Lincoln James, Interactivity Reexamined: A Baseline Analysis of Early Business Web Sites, Journal of Broadcasting and Electronic Media, Vol. 42, No. 4, pp. 457-469, 1988.

16. Hwang, Jang-Sun, Sally MacMillan and Guiohk Lee, Corporate Web Sites as Advertising: An Analysis of Function, Audience and Message Strategy, Journal of Interactive Advertising, Vol. 3, No. 2, 2003, at http://jiad.org/vol3/no2.

17. Joreskog, Karl and Dag Sorbom, LISREL 8: Structural Equation Modeling with the SIMPLIS Command Language. Chicago, IL: Scientific Software, 1993.

18. Kumar, Nirmalya, Louis Stern, and Ravi Achrol, Assessing Reseller Performance from the Perspective of the Supplier, Journal of Marketing Research, Vol. 29, May, pp. 238-53, 1992.

19. Li, Hairong and Janice Bukovac, Cognitive Impact of Banner Ad Characteristics: An Experimental Study, Journalism and Mass Communication Quarterly, Vol. 76, No. 2, Summer, pp. 341-353, 1999.

20. Mackenzie, Scott, Richard Lutz and George Belch, The Role of Attitude toward the Ad as a Mediator of Advertising Effectiveness: A Test of Competing Explanations, Journal of Marketing Research, Vol. 23, May, pp. 130-143, 1986.

21. Maheswaran Durairaj and Sternthal Brian, The Effects of Knowledge, Motivation and Type of Message on Ad Processing and Product Judgments, Journal of Consumer Research, Vol. 17, No.1, June, pp. 66-73, 1990.

22. Martin, Brett, Michael Sherrard and Daniel Wentzel, The Role of Sensation Seeking and Need for Cognition on Web-Site Evaluations: A Resource-Matching Perspective, Psychology and Marketing, Vol. 22, No. 2, February, pp. 109-126, 2005.

23. Mitchell Andrew, The Effect of Verbal and Visual Components of Advertisements on Brand Attitudes and Attitudes towards the Advertisement, Journal of Consumer Research, Vol. 13, June, pp. 12-24, 1986.

24. Mitchell, Andrew and Jerry Olson, Are Product Attribute Beliefs the Only Mediator of Advertising Effects on Brand Attitude? Journal of Marketing Research, Vol. 18, August, pp. 318-332, 1981.

25. Petty, Richard and John Cacioppo, Attitudes and Persuasion: Classic and Contemporary Approaches, Dubuque, IA: William C. Brown, 1981. 
26. Petty, Richard, John Cacioppo and David Schumann, Central and Peripheral Routes to Advertising Effectiveness: The Moderating Role of Involvement”, Journal of Consumer Research, Vol. 10, September, pp. 135-146, 1983.

27. Sicilia, Maria, Salvador Ruiz and Nina Reynolds, Attitude Formation Online: How the Consumer's Need for Cognition Affects the Relationship between Attitude Towards the Website and Attitude the Brand, International Journal of Market Research, Vol. 48, No. 2, pp. 139-154, 2006.

\section{NOTES}

